Article

\title{
Do High-Performance Work Systems Really Satisfy Employees? Evidence from China
}

\author{
Po-Chien Chang, Ting Wu * and Chen-Lin Liu
}

School of Business, Macau University of Science and Technology, Macau 519020, China; pcchang@must.edu.mo (P.-C.C.); liuchenlin1122@163.com (C.-L.L.)

* Correspondence: twu@must.edu.mo; Tel.: +86-853-88971930

Received: 3 July 2018; Accepted: 17 September 2018; Published: 20 September 2018

\begin{abstract}
Our study aims to examine the outcomes of Western-based high-performance work systems (HPWS) from two separate workplace events (job discretion and work intensification) in a Chinese context. Based on Affective Events Theory (AET), employee reactions and job satisfaction may vary depending on their working environment. We applied hierarchical linear modeling (HLM) to analyze data collected from 34 human resources managers and 354 employees working in the Chinese manufacturing and service industries. Our study demonstrates that workplace events based on HPWS may influence employees' feelings and job satisfaction. Job discretion makes employees feel positive and increases their job satisfaction while work intensification is seen as negative by employees and reduces their job satisfaction. However, results also show that HPWS fail to bring increased satisfaction to employees due to job discretion. This study supports previous studies that not all HPWS may lead to positive outcomes when internal stakeholders' well-being is not considered. Without considering long-term investment in employees, it is challenging for organizations to maintain their competitiveness and meet their goals. Further research is suggested to include more study of different contexts and time frames while examining the outcomes of HPWS.
\end{abstract}

Keywords: high-performance work systems (HPWS); affective events theory (AET); job discretion; work intensification; job satisfaction

\section{Introduction}

Over the past two decades, strategic human resource management (SHRM) has focused on management practices—such as high-performance work systems (HPWS)—supporting organizations to attain strategic goals, particularly with market and financial outcomes [1-4]. HPWS are a bundle of human resource management (HRM) practices-including selective recruitment and selections; incentive compensation; employee development; and participative decision-making — which aim to advance employee abilities, motivation, and opportunities for better organizational benefits [5-9]. According to the mutual gains view, organizations adopting HPWS may positively influence employee attitudes (e.g., increased job satisfaction, greater commitment) and improve well-being (e.g., reduced turnover) [1,2,9-11]. These cost-efficient results regarding employees may lead to organizational profitability through motivators, such as autonomy and teamwork $[2,9,11,12]$.

Nevertheless, there are different views about the impact of HPWS on employees [13]. For instance, the critical perspectives on HPWS starts to recognize the downside of these systems on human and social outcomes rather than on financial performance $[4,9,14]$. This critical view suggests that organizational performance may be offset at the expense of employees' longer working hours and greater work intensification; bring additional pressure on other stakeholders (e.g., employees' family members and communities) [4,15-18]. Additionally, this perspective emphasizes the role of employees in facilitating financial as well as other impacts on organizational members (human) and relationships 
among people (social) [12,19]. Related research has shifted the focus to the term 'sustainable HRM' considering aspects including the systems and their effects on people. Sustainable HRM deals with social and environmental concerns in business operation while interacting with multiple stakeholders [12]. Though the definition of sustainable HRM still lacks agreement, research mainly focuses on managing human resources to meet the optimal needs of organizations and the community without losing the organization's ability to meet future needs $[13,20]$. Sustainability is composed of three pillars-namely economic, social, and environmental-that concern economic growth as well as ethical and legal responsibilities of organizations [12]. Organizations therefore, not only have to consider internal and external but short- and long-term impacts on multiple stakeholders. Although organizations realize the significance of considering the well-being of multiple stakeholders, there is little evidence that organizations not only improve performance through HPWS but attempt to lessen any harmful influences on employees [20].

The resource-based view has stated the importance of employees as scarce and valuable resources for attaining sustainable competitive advantage [14]. To maintain and retain the valued human talents, it is necessary to consider employee responses and feedback (e.g., affective states) toward organizational practices (e.g., HPWS) to create a work environment that improves employee motivation for higher levels of efficiency [13]. How organizations apply sustainability to practically execute HRM practices still needs further investigation. To delve into the impacts of HPWS on employees, we specifically focus on emotion and affective experiences in the workplace [21]. According to AET, employee affective states may be influenced by specific workplace events and may cause further attitudinal reactions. In this study, both positive (i.e., job discretion) and negative (i.e., work intensification) events from HPWS are investigated, particularly regarding workplace environments generating positive (e.g., happy, satisfying) and negative (e.g., frustrating, disappointing) affective states, which further influence employees' attitudes toward their jobs (i.e., job satisfaction).

Therefore, this study aims to bring empirical evidence in examining positive and negative effects of HPWS on employees in a Chinese context to bridge the research gap and it is organized as follows. To begin with, we briefly introduce the origins of sustainable HRM followed by SHRM. Two contrasting perspectives (i.e., mutual gains and critical views) are included to examine the influences of HPWS on employees' affective states through two workplace events (i.e., job discretion and work intensification) [8]. Next, we examine the relationship between two workplace events from HPWS and employees' job satisfaction through their affective reactions based on AET. Sustainable HRM as a basis includes human and social aspects other than financial outcomes, clarifying the outcomes of Western-based HPWS implemented by Chinese enterprises. This is followed by a conclusion based on the shift in employment relations during transformation from a planned economy to relatively free market in Chinese society [8].

\section{Literature Review}

\subsection{The Relationship between Sustainability and Human Resource Management (HRM)}

Introduced in 1987-sustainability or sustainable development—is defined as "ensuring that it meets the needs of the present without compromising the ability of future generations to meet their own needs" [22]. By this definition, organizations looking for sustainable competitive advantage should consider the impact on multiple stakeholders from long-term and maintainable perspectives [13,20,22]. To ensure the implementation of sustainable development, organizational practices should include a so-called triple bottom line view (i.e., people, planet, profits) which considers social needs, environmental protection, and the prospective economy $[18,20]$. Despite the multiple concerns, employees as internal stakeholders are the fundamental factors for creating valuable and unique intangible resources to attain sustainable competitive advantage [18]. Until recently, researchers addressed the social and human factors with a solely performance-focus $[13,20]$. Thus, a sustainable 
company must take care of economic development, social relationships among stakeholders, and the natural environment based on both short- and long-term views while running their business [22,23].

Sustainable HRM refers to a bundle of human resource (HR) practices that aim to maximize organizational profits and reduce negative impacts on employees, their families, and communities to satisfy future needs [20,23]. That is to say, organizations aiming for sustainable competitive advantage must adopt HR practices-such as HPWS - as vehicles to promote excellent organizational performance. In line with a mutual gains perspective, the purposes of HPWS-including participative decision-making, teamwork, learning, and development-lie in attracting, obtaining, and maintaining valuable HRs which are beneficial to both employee well-being and organizational performance based on a future-focus $[5,20]$. As a growing trend in the field of management, sustainable HRM may be a critical way to meet the needs of the triple bottom line in future.

\subsection{Western-Based HPWS in Chinese Contexts}

In addition to different stakeholders, research into sustainable HRM, also needs to take into consideration the contexts. Most studies in this area are based on Western views without including cross-cultural aspects. China-as a relatively fast-growing country-has employment systems which are deeply affected by its unique cultural and social background which is distinctive from the Western world [11]. Multiple HRM systems—-such as HPWS—which are commitment-based, and control-based, co-exist in organizations to improve their competitiveness [11,13]. Nevertheless, previous studies which examined the effectiveness of HPWS [4,10-12,15,24] show mixed results without consideration of the context and development process of China. Deeply influenced by paternalism and familialism, the institutional and authoritarian backgrounds have profound impacts on employment relationships in China [10]. Under a high power distance society, practices such as participative decision-making and job discretion in HPWS may bring challenges and extra demands because Chinese employees are used to being led by management rather than making decisions on their own $[8,10,24]$. It is important for researchers to consider context factors when they are examining the effectiveness of HPWS in China.

\subsection{The Application of Affective Events Theory (AET)}

The aim of HPWS is to treat employees as valuable and talented by taking care of their well-being. A bundle of practices-such as training, team work, and participative decision-making-are likely to bring relatively positive affect workplace experiences. Even though this positive affect may be important, few studies have examined the affective or emotional factors relating to HPWS and employee outcomes $[21,25,26]$. Developed in the mid-1990s, AET assumes that the context of the workplace generates certain events that stimulate various affective reactions and further influences employee attitudes and behavior [25]. Though AET does not mention specific workplace features and work events that might trigger affective responses, studies support the positive relationship between employees' perceptions regarding organizational practices and affective reactions $[25,26]$. In this study, organizations signal their concerns about employee well-being and tend to build long-term relationships based on HPWS. The concerns are assumed to bring positive affective reactions and cognitive judgment (e.g., job satisfaction) to the workplace $[25,26]$. Therefore, this study investigates employee job satisfaction (i.e., attitudes) influenced by both the cognitively evaluated work environment (i.e., HPWS) and by affective states experienced from work events (i.e., work intensification and job discretion) [21,27].

\subsection{Research Hypothesis}

HPWS is a set of consistent practices designed to encourage employees to actively contribute to the fulfillment of organizational objectives [10]. Based on previous discussion, practices such as decision-making, training, and development are supposed to enhance employee skill, motivation, and empowerment [28]. Job discretion is one of the practices, where employees are given control over tasks and work schedules. Employees perceive higher degrees of control over when and 
how they organize and schedule their tasks as helping them to deal with the demands of their job and this leads to less mental strain $[29,30]$. Based on AET, work environment characteristics affect the occurrence of some events, and these events engender employee affective responses [21,26]. Job discretion in this study is taken as an important aspect of HPWS that may influence affective experiences of employees due to participative decision-making and a greater degree of control over work schedules [4,7]. When individuals perceive an increase in the scope of job discretion (e.g., job autonomy and task delegation) - either from these practices or from managerial leadership which redesigns and reorganizes tasks-it can create positive feelings toward the workplace $[4,9,31,32]$. Thus, the following hypothesis is put forward:

\section{Hypothesis 1. The positive relationship between HPWS and positive affect is mediated by job discretion.}

Most HPWS studies show that organizational performance comes from employee contributions through a set of consistent HRM practices which increase their abilities, motivations, and opportunities [1-3,5]. However, with the growing focus on the responsibility of organizations, the influence of HPWS may lead to an unexpectedly negative influence, such as work-overload [28,33]. Based on the critical view, the improvement of organizational performance from the implementation of HPWS may be achieved by means of employee high-involvement and commitment $[9,10]$. This may in turn lead to employees experiencing high job demands $[9,10]$. Resource depletion from intensified work is associated with negative affective states due to unmet requirements [15,25]. If employees receive higher work demands and pressure than they can manage, they are more likely to experience higher levels of work intensification. This can be harmful to employees and may bring negative affect. The debate then becomes whether HPWS improvements in efficiency of production or increased employee work intensification is seen as worthwhile in return for the extent of discretion the employees have gained over their work $[6,9,17,27]$. The following hypothesis is therefore put forward:

Hypothesis 2. The positive relationship between HPWS and negative affect is mediated by work intensification.

Based on AET, workplace events may cause different affective states (i.e., positive or negative) that impact on employee attitudes $[21,26]$. Studies show that affective states are related to how employees think and feel about their workplace (i.e., work attitudes) [21,34]. Thus, it is likely that desirable workplace events will stimulate positive affective reactions. Job discretion that helps employees initiate actions to arrange their working conditions and - to a degree-work content is assumed to be valued by employees, since it not only shows that the organization has concern for their well-being but also trusts their capability to manage [26]. Job satisfaction representing employee evaluative judgment about jobs is one of the most indicators regarding workplace $[21,25,26]$. Previous research showed that a positive affect is an important antecedent of job satisfaction, meaning that workplace features may influence judgment of job characteristics by means of cognitive evaluations of desirable events. Based on staff working in call centers, one UK study showed that an organization providing job discretion to its employees positively influenced their overall judgments about their job satisfaction, as the employees took the job arrangements as signs of recognition and trust by the organization $[21,25,26,34]$. The following hypothesis is therefore put forward:

Hypothesis 3. The positive relationship between job discretion and job satisfaction is mediated by positive affect.

Studies into the negative effects of HPWS, show that critical perspectives assume that a great degree of work involvement and dedication are associated with higher levels of work intensification, with negative impacts on employees $[4,9,10]$. The concerns are that implementing HPWS may increase work intensity and negative affect, increasing anxiety and stress due to excessive demands or resource depletion $[6,17,27]$. We shall examine how HPWS affect employee well-being in different ways. Previous research implies that the physical and psychological health of employees is at risk when 
they experience high levels of work demands in the workplace [4,6,14]. A high degree of work intensification depletes an individual's ability to manage unmet requests and unexpected incidents. By re-arranging time and reorganizing schedules to achieve organizational goals, work intensification may cause negative affective responses since employees are burdened with unmet demands at work. In turn, higher levels of work intensification with work-overload and longer working hours may further lower job satisfaction $[16,17,34,35]$. Therefore, the following hypothesis is put forward with the hypothesized model presented in Figure 1.

Organizational-level

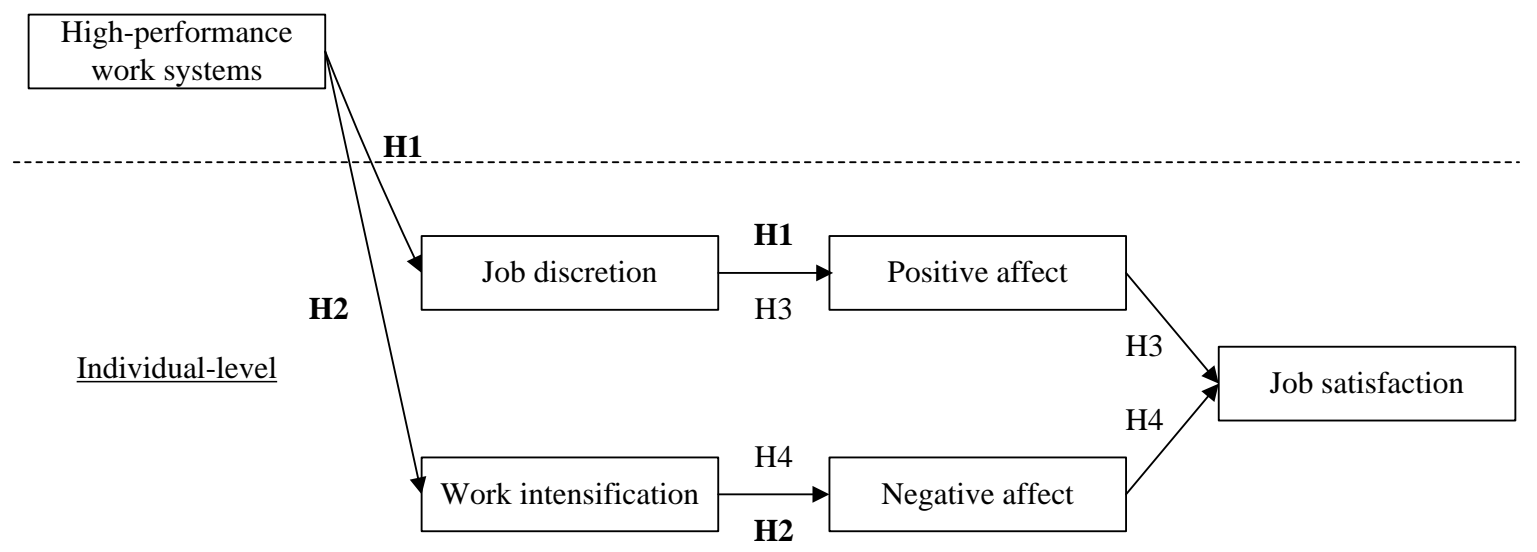

Figure 1. The hypothesized model.

Hypothesis 4. The negative relationship between work intensification and job satisfaction is mediated by negative affect.

The hypothesized model is presented in Figure 1.

\section{Research Method}

Previous literature demonstrates the relationship between sustainable HRM, HPWS, and their related influences. Subsequently, this study aims to contribute by examining the influence of the HPWS on employee affective states and their job satisfaction regarding a given context.

\subsection{Samples and Data Collection Procedure}

Questionnaires were collected from manufacturing and service industries located in Anhui, Guangdong, and Shandong provinces in China. Respondents included HR managers and employees. The HR manager of each organization provided information about HPWS and organizational characteristics, while employees provided data regarding job discretion, work intensification, positive affect, negative affect, job satisfaction, and demographic information. This study was limited to employees in the departments of research and development; and sales and marketing. The reason for this was that these professionals were assumed to have more decision-making opportunities in their organizations. Therefore, these were the most appropriate departments in which to test the hypotheses.

In total, $50 \mathrm{HR}$ manager surveys and 1000 employee surveys were distributed; $35 \mathrm{HR}$ manager and 365 employee surveys were collected. Removal of surveys with missing information resulted in a final sample of 354 employees from 34 organizations. The valid response rate for employees was 35.4 percent and for organizations was 68 percent. The organizations in the sample were 14 organizations from the service industry (i.e., hospitality, healthcare, finance, and insurance) and 20 organizations were from the manufacturing industry (i.e., electrical equipment; appliances; components; computer and electronics; and petroleum and chemicals). Nineteen organizations were state-owned, and 15 organizations were 
privately owned enterprises; 12 organizations had 500 or fewer employees, nine organizations had between 501 and 1000 employees, nine organizations had between 1001 and 3000 employees, and four organizations with over 3000 employees. Of the 354 employees, males accounted for 61.9 percent and females accounted for 38.1 percent; 75.7 percent had attained a bachelor's degree; 68.6 percent were married and there was an average tenure was 12.2 years. The average tenure for HR managers was 8.9 years and 35 percent were male.

\subsection{Measures}

HPWS. Based on the HPWS concept [7], Ramsay et al.'s [4] questionnaire was, in part adopted, covering five sub-dimensions (sophisticated recruitment and selection; formal training systems; job security; performance appraisal; and team autonomy). HR managers in each organization were asked to rate these on a five-point Likert scale ranging from one ("strongly disagree") to five ("strongly agree"). A sample item from this scale is "There has been training in non-technical skills (e.g., problem-solving, communication)". The Cronbach's alpha for this scale was 0.70 .

Job discretion. Job discretion was assessed with a three-item questionnaire based on Ramsay et al.'s [4] study. The scale used a five-point Likert-type scale ranging from one ("Just a little") to five ("Almost all"). Higher scores reflect higher job discretion. A sample item from this scale is "Your degree of influence in the range of tasks". The Cronbach's alpha for this scale was 0.82 .

Work intensification. The questions from Ramsay et al.'s [4] study were adopted for measuring this construct and the item wording was slightly modified from the original measure. Respondents were asked to assess the degree of change in their labor productivity in the past year. The scale used a five-point Likert-type scale ranging from one ("gone down a lot") to five ("gone up a lot").

Positive affect. Positive affect at work was measured with a five-item questionnaire developed by Burke et al. [36]. Respondents were asked to assess how often they were feeling strong, determined, attentive, inspired, and active during the previous week. The scale used a five-point Likert-type scale ranging from one ("Very slightly or not at all") to five ("Extremely"). The Cronbach's alpha for this scale is 0.91 .

Negative affect. Negative affect at work was measured with a five-item questionnaire developed by Burke et al. [36]. Respondents were asked to assess how often they were feeling guilty, nervous, jittery, scared, and afraid during the previous week. The scale used a five-point Likert-type scale ranging from one ("Very slightly or not at all") to five ("Extremely"). The Cronbach's alpha for this scale is 0.86 .

Job satisfaction. Job satisfaction was assessed with a five-item questionnaire developed by Brayfield and Rothe [37]. The scale used a five-point Likert-type scale ranging from one ("Strongly disagree") to five ("Strongly agree"). Higher scores reflect higher job satisfaction. A sample item from this scale is "Most days I am enthusiastic about my work." The Cronbach's alpha for this scale is 0.71 .

Control variables. Organization size, type of industry, type of ownership, gender, and tenure from organizational and individual levels were included as control variables. The type of industry $(0=$ manufacturing industry; $1=$ service industry $)$, type of ownership $(0=$ state-owned enterprise; 1 = privately owned enterprise $)$ and gender $(0=$ female; $1=$ male $)$ were coded as dummy variables. In addition, because of the skewed nature, the natural log of organizational size was used to normalize their distribution.

\section{Results}

The mean (M), standard deviations (SD), and correlations among variables both at individual and the organizational levels are reported in Table 1. 
Table 1. Mean, standard deviation, and zero-order correlations for all study variables.

\begin{tabular}{|c|c|c|c|c|c|c|c|c|}
\hline Variables & $\mathbf{M}$ & SD & 1 & 2 & 3 & 4 & 5 & 6 \\
\hline \multicolumn{9}{|l|}{ Organizational level } \\
\hline 1. HPWS & 3.48 & 0.21 & & & & & & \\
\hline 2. Industry & 0.41 & 0.50 & 0.04 & & & & & \\
\hline 3. Ownership & 0.44 & 0.50 & 0.14 & 0.34 * & & & & \\
\hline 4. Size & 6.79 & 1.04 & 0.02 & $0.73^{* * *}$ & $0.75^{* * *}$ & & & \\
\hline \multicolumn{9}{|l|}{ Individual-level } \\
\hline 1. Gender & 0.62 & 0.49 & & & & & & \\
\hline 2. Tenure & 12.24 & 9.46 & 0.08 & & & & & \\
\hline 3. Job discretion & 3.07 & 0.71 & 0.02 & -0.05 & & & & \\
\hline 4. Work intensification & 2.83 & 1.08 & -0.09 & -0.05 & -0.03 & & & \\
\hline 5. Positive affect & 2.97 & 0.85 & -0.10 & -0.50 & $0.20^{* * *}$ & -0.03 & & \\
\hline 6. Negative affect & 1.82 & 0.58 & 0.05 & $0.13^{*}$ & 0.01 & $0.13 *$ & $-0.28^{* * *}$ & \\
\hline 7. Job satisfaction & 3.30 & 0.59 & -0.03 & $-0.14^{* *}$ & $0.17^{* *}$ & $-0.15^{* *}$ & $0.31^{* * *}$ & $-0.39^{* * *}$ \\
\hline
\end{tabular}

Notes: For organizational-level measures, $\mathrm{N}=34$; For individual-level measures, $\mathrm{N}=354 .{ }^{*} p<0.05,{ }^{* *} p<0.01$, ${ }^{* * *} p<0.001$ 


\subsection{Cross-Level Mediating Effect of Job Design and Work Intensification}

This study applied hierarchical linear modeling (HLM)—a statistical approach which can simultaneously estimate the relationships between different levels of variables consisting of nested data-as an analytical tool. At first, we followed Hofmann's [38] suggestions to examine whether any significance between organizations exists in terms of dependent variable. Thus, using HLM, we estimated a null model in which no predictors were specified for either the Level 1 or the Level 2 function to test the significance level of the between-organizations variance in the outcome by examining the significance level of the Level 2 residual variance of the intercept $\left(\tau_{00}\right)$ and ICC1. Results showed that there was significant between-organizations variance for positive affect $\left(\tau_{00}=0.12\right.$, $p<0.001)$ and negative affect $\left(\tau_{00}=0.10, p<0.001\right)$, respectively. After calculation, the ICC 1 were 0.17 and 0.29 , respectively, indicating that 17 percent of the variance in positive affect resided between organizations and 29 percent of the variance in negative affect between organizations. We thus proceeded to test our hypotheses using HLM.

Hypotheses 1 and 2 predicted that job discretion mediates the relationship between HPWS and positive affect as well as the work intensification mediated the relationship between HPWS and negative affect, respectively. Since our data structure was multilevel in nature, we not only followed Baron and Kenny's [39] procedures for assessing statistical mediation but also adopted a $2 \rightarrow 1 \rightarrow 1$ model — the three numbers indicating that the initial Level 2 variable (i.e., HPWS), Level 1 mediator (i.e., job discretion, work intensification), and Level 1 outcome variable (i.e., positive affect, negative affect)—proposed by Krull and MacKinnon [40] to test the cross-level mediating effect for our Hypothesis 1 and 2.

Tables 2 and 3 present the results of the HLM analyses conducted to test our Hypotheses 1 and 2. Table 2 shows that three preconditions (i.e., a significant relationship between the independent and dependent variable; a significant relationship between the independent variable and the mediator; a significant relationship between the mediator and the dependent variable) proposed by Baron and Kenny [34] were not satisfied before the cross-level mediating effect of job discretion was tested. Hence, Hypothesis 1 does not receive support. The results in Table 3 show that three preconditions were satisfied before the cross-level mediating effect of work intensification was tested. By comparing the effect on negative affect in Model 1 and Model 4, it was found that the effect of HPWS on negative affect dropped from $0.141(p<0.001)$ to $0.138(p<0.001)$, showing that the relationship between HPWS and negative affect is partially mediated by work intensification. Thus, Hypothesis 2 was supported. Furthermore, a Sobel test revealed that the indirect path linking HPWS and negative affect through work intensification was significant $(Z=1.66, p<0.1)$.

Table 2. Summary of mediation analyses among HPWS, job discretion, and positive affect.

\begin{tabular}{cccc}
\hline Predictors & $\begin{array}{c}\text { Model 1 } \\
\text { HPWS } \rightarrow \text { PA }\end{array}$ & $\begin{array}{c}\text { Model 2 } \\
\text { HPWS } \rightarrow \text { JD }\end{array}$ & $\begin{array}{c}\text { Model 3 } \\
\text { JD } \rightarrow \text { PA }\end{array}$ \\
\hline Intercept & $2.74^{* *}$ & $1.82^{* *}$ & $2.98^{* *}$ \\
Organizational level & & $-0.45^{* *}$ & -0.02 \\
Industry & -0.16 & -0.16 & -0.14 \\
Ownership & -0.13 & $0.23^{*}$ & 0.03 \\
Size & 0.07 & 0.15 & \\
HPWS & $-0.76^{*}$ & & $-0.23^{* *}$ \\
Employee level & & 0.04 & -0.00 \\
Gender & $-0.20^{*}$ & -0.01 & $0.22^{* *}$ \\
Tenure & -0.00 & &
\end{tabular}

Note: HPWS: high-performance work systems, JD: job discretion, PA: positive affect. ${ }^{*} p<0.05,{ }^{* *} p<0.01$. 
Table 3. Summary of cross-level mediation analyses among HPWS, work intensification, and negative affect.

\begin{tabular}{ccccc}
\hline Predictors & $\begin{array}{c}\text { Model 1 } \\
\text { HPWS } \rightarrow \text { NA }\end{array}$ & $\begin{array}{c}\text { Model 2 } \\
\text { HPWS } \rightarrow \text { WI }\end{array}$ & $\begin{array}{c}\text { Model 3 } \\
\text { WI } \rightarrow \text { NA }\end{array}$ & $\begin{array}{c}\text { Model 4 } \\
\text { HPWS, WI } \rightarrow \text { NA }\end{array}$ \\
\hline Intercept & $1.11^{*}$ & $3.72^{* *}$ & $1.71^{*}$ & $1.05^{*}$ \\
Organizational level & & & & \\
Industry & $-0.26^{*}$ & 0.05 & -0.11 & $-0.26^{*}$ \\
Ownership & -0.07 & 0.28 & 0.12 & -0.09 \\
Size & 0.11 & -0.13 & 0.00 & 0.12 \\
HPWS & $1.41^{* * *}$ & $0.63^{*}$ & & $1.38^{* * *}$ \\
Employee level & & & & 0.08 \\
Gender & 0.07 & -0.16 & 0.09 & 0.00 \\
Tenure & 0.00 & -0.00 & 0.00 & $0.06^{*}$ \\
Work intensification & & & $0.08^{* *}$ &
\end{tabular}

Note: HPWS: high-performance work systems, WI: work intensification, NA: negative affect. ${ }^{*} p<0.05,{ }^{* *} p<0.01$, $* * * 0.001$.

\subsection{Mediating Effect of Positive Affect and Negative Affect}

Following Baron and Kenny's [39] guidelines on mediation tests, Table 4 shows that three preconditions were satisfied before the mediating effect of positive affect was tested. Subsequently, by comparing the effect on job discretion in Model 1 and Model 4, the regression coefficient associated with job discretion becomes smaller and the significant level declines when positive affect is included in the model (from $\beta=0.16, p<0.01$, to $\beta=0.10, p<0.05$ ). Thus, Hypothesis 3 was supported. Furthermore, a Sobel test revealed that the indirect path linking job discretion and job satisfaction through positive affect was significant $(Z=3.15, p<0.01)$.

Table 4. Summary of mediation analyses among job discretion, positive affect, and job satisfaction.

\begin{tabular}{ccccc}
\hline Predictors & $\begin{array}{c}\text { Model 1 } \\
\text { JD } \rightarrow \text { JS }\end{array}$ & $\begin{array}{c}\text { Model 2 } \\
\text { JD } \rightarrow \text { PA }\end{array}$ & $\begin{array}{c}\text { Model 3 } \\
\text { PA } \rightarrow \text { JS }\end{array}$ & $\begin{array}{c}\text { Model 4 } \\
\text { JD, PA } \rightarrow \text { JS }\end{array}$ \\
\hline Gender & -0.03 & $-0.10^{*}$ & 0.01 & 0.00 \\
Tenure & $-0.13^{*}$ & -0.03 & $-0.13^{*}$ & $-0.12^{*}$ \\
Job discretion & $0.16^{* *}$ & $0.20^{* * *}$ & & $0.10^{*}$ \\
Positive affect & & & $0.30^{* * *}$ & $0.28^{* * *}$ \\
\hline
\end{tabular}

Note: JD: job discretion, PA: positive affect, JS: job satisfaction. ${ }^{*} p<0.05,{ }^{* *} p<0.01,{ }^{* * *} p<0.001$.

Table 5 also shows that three preconditions were satisfied before the mediating effect of negative affect was tested. Subsequently, by comparing the effect on job discretion in Model 1 and Model 4, the regression coefficient associated with work intensification becomes smaller and the significance level declines when positive affect is included in the model (from $\beta=-0.17, p<0.01$, to $\beta=-0.11$, $p<0.05)$, Thus, Hypothesis 4 was supported. Furthermore, a Sobel test revealed that the indirect path linking work intensification and job satisfaction through negative affect was significant $(Z=-2.90$, $p<0.05)$. Table 6 shows the results of the four hypotheses. Except for Hypothesis 1 demonstrating the mediation among HPWS, job discretion, and positive affect, the other three were supported. 
Table 5. Summary of mediation analyses among work intensification, negative affect, and job satisfaction.

\begin{tabular}{ccccc}
\hline Predictors & $\begin{array}{c}\text { Model 1 } \\
\text { WI } \rightarrow \text { JS }\end{array}$ & $\begin{array}{c}\text { Model 2 } \\
\text { WI } \rightarrow \text { NA }\end{array}$ & $\begin{array}{c}\text { Model 3 } \\
\text { NA } \rightarrow \text { JS }\end{array}$ & $\begin{array}{c}\text { Model 4 } \\
\text { WI, NA } \rightarrow \text { JS }\end{array}$ \\
\hline Gender & -0.04 & 0.06 & -0.01 & -0.02 \\
Tenure & $-0.14^{* *}$ & $0.14^{*}$ & -0.09 & -0.09 \\
Work & $-0.17^{* *}$ & $0.17^{* *}$ & & $-0.11^{*}$ \\
intensification & & & $-0.38^{* * *}$ & $-0.36^{* * *}$ \\
Negative affect & & & \\
\hline Note: WI: work intensification, NA: negative affect, JS: job satisfaction. ${ }^{*} p<0.05^{* *} p<0.01,{ }^{* * *} p<0.001$.
\end{tabular}

Table 6. Summary of the analytical results for all research hypotheses.

\begin{tabular}{ccc}
\hline \multicolumn{1}{c}{ Path } & Research Hypothesis & Analytical Results \\
\hline $\mathrm{HPWS} \rightarrow \mathrm{JD} \rightarrow \mathrm{PA}$ & $\mathrm{H} 1$ & Not supported \\
$\mathrm{HPWS} \rightarrow \mathrm{WI} \rightarrow \mathrm{NA}$ & $\mathrm{H} 2$ & Supported \\
$\mathrm{JD} \rightarrow \mathrm{PA} \rightarrow \mathrm{JS}$ & $\mathrm{H} 3$ & Supported \\
$\mathrm{WI} \rightarrow \mathrm{NA} \rightarrow \mathrm{JS}$ & $\mathrm{H} 4$ & Supported
\end{tabular}

Note: HPWS: high-performance work systems, JD: job discretion, WI: work intensification, PA: positive affect NA: negative affect, JS: job satisfaction.

\section{Discussions}

This study addresses the recent focus to improve employee well-being to attain organizational sustainable competitive advantage. This research contributes to the growing number of HPWS studies in many ways and brings the following key implications. First, we include both mutual gain and critical views when examining the outcomes of HPWS. On the one hand, mutual gain perspective indicates that this set of HR practices aims to produce beneficial organizational results by means of positive relationships with employees [5,9]. On the other hand, the critical perspective emphasizes the benefits generating by HPWS for organizations may be accrued by intensifying workload and decreasing work-life quality. To investigate the dilemma of HPWS, most studies have mainly focused on employee cognitive perceptions of organizational surroundings despite the occurrence of affect being taken as an important antecedent to individual attitudes and behavior [26]. Thus, to obtain evidence regarding the effectiveness of HPWS, this study includes the AET to explore the relationship between HPWS and employee attitudes. Based on AET, HPWS is an important workplace environment-including workplace events (i.e., job discretion and work intensification)— that could determine employee affective experiences and work-related attitudes $[4,15,21,25,33]$.

Our findings show that negative affect is generated because of increasing job demands and working hours (i.e., work intensification) due to HPWS (Hypothesis 2). The result is consistent with the critical view that the improved organizational effectiveness mainly derives from making more effort and greater involvement by higher levels of work intensification. Furthermore, the results also show that negative affect caused by work intensification may consequently result in more negative work-related attitudes (i.e., job satisfaction) (Hypothesis 4). It reflects the critical views that HPWS - by motivating greater involvement and participation-may lead to added responsibilities and extra workloads to attain organizational financial outcomes at the expense of employee well-being $[4,6,14,16,30,33,41]$. Originally, the ultimate purpose of HPWS was for good people management to lead to better organizational performance [20]. In seeking cost-effectiveness, enterprises implementing HPWS may bring extra workload, work intensification, and stress that result in lower job satisfaction and even labor exploitation [8,10,41-43]. Tensions between management and employees due to disappointing relationships and decreasing work-life quality may be detrimental to building harmonious workplaces for longer term development [41].

Regarding a mutual gains view, the result fails to support that job discretion derived from HPWS brings positive affective experiences to employees (Hypothesis 1); though job discretion 
brings positive affect and higher job satisfaction (Hypothesis 3) [5,21,30,33,35]. Unlike previous studies, our results did not support the positive relationship between HPWS and employee responses (c.f. [34]). HPWS emphasize the importance of treating employees as valuable resources and caring for their well-being. HPWS can be a vehicle to convey organizations' willingness to build long-term relationship based on training, teamwork, participation, and involvement $[9,31,34]$. Ideally, HPWS are designed to stimulate positive affect because these practices allow employees to actively participate in organizational decisions with greater control through job discretion, [9,31,34]. These practices are thought to encourage employee dedication and increase their attachment with organizations to attain organizational objectives $[9,20]$. However, when taking the context into consideration, our results show that the Western-based HPWS did not bring positive affect to employees in the Chinese enterprises (Hypothesis 1). In past decades, China has experienced a transformation from a command to a market-driven economy, and this is thought to have created unique employment relations and management systems for Chinese enterprises [43]. In addition to business operation under globalization, Confucianism has been deeply embedded in Chinese society to shape values and behaviors $[13,14,43]$. Thus, when applying Western-based HPWS to Chinese enterprises, contextual issues need to be stressed since both internal and external elements-such as economic development, system transformation, demographic changes, and cultural traditions-may influence the success of implementation $[8,14,33,43]$. In a relatively collective and higher power distance society, such as China, HPWS which encourage employees to actively participate in decision-making, or even to make decisions on their own, may challenge their values and beliefs in the need to compromise or comply with the norms and rules of a group. Chinese employees are used to following the orders of supervisors and obeying group norms to maintain good supervisor-subordinate interactions so they are more efficient in the workplace [13]. Good interpersonal relationships (i.e., Guanxi) as a key to retaining talents will actively create a harmonious workplace, and further achieve effective performance [13].

Recently, emerging sustainable HRM focuses on both improving overall performance and lessening the negative impacts on employee well-being through HPWS to meet future needs $[12,13]$. Previous studies show that poor working relations may lead to negative effects on employee affect and behavior and may cause psychological strain [13]. Consistent with sustainable HRM, it is an organizations' responsibility to take different stakeholders' interests into consideration to create a harmonious work environment. The reciprocal relationship is mainly based on respect paid to supervisors while supervisors take care of subordinates' well-being [13]. To build durable employment relationships, employee reactions and feedback serve as the basic but crucial elements for organizations to obtain and retain talent $[9,13]$. By means of frequent and close interactions from multiple communication channels, misunderstandings-such as taking contracts as non-negotiable and a sense of a commodity-like relationship may be decreased $[31,33,43]$. HR practitioners may encourage the transparency of systems, by adopting multiple communication mechanisms for feedback, seeking process, and better negotiation. Contemporary Chinese enterprises adopting practices such as job discretion and participatory decision-making may re-examine the application of Western-based HPWS, and their related positive and negative outcomes [13,41]. Management should relinquish power, encourage self-management, and empowerment in decision-making; while employees need to get used to having a voice, to prompting feedback, and to collaborative teamwork [8,44]. Both management and employees must make efforts to re-shape the employment relationship.

\section{Limitations and Future Research Directions}

This study has limitations that need further exploration. Firstly, the data were collected from manufacturing and service industries located in Anhui, Guangdong, and Shandong provinces in China. Though the final response rate was acceptable, based on previous research, there are still ways to improve for future research [45]. For instance, an improvement would be to contact participants multiple times, with clear notifications being repeated, re-contacting respondents would help to ensure a good response rate. Also, the design of the survey may be improved to make it less time-consuming 
to complete. To improve the response rate, future studies should make good use of the prevalence of mobile phone usage in China. Web surveys may be a good facilitator for collecting data across provinces in China [45].

In addition, although we tried our best to collect the data from different sources, certain data were still obtained from a single source (i.e., employees) by using a self-reporting questionnaire. This may cause a common method variance problem [46]. To reduce this method bias, future research may be improved through separating the measurement of different variables (i.e., predictor variable, mediator variable, or criterion variable) and introducing a time lag between the measurement of the predictor, mediator, and outcome variables [47]. Moreover, affective response is dynamic and may change at different time periods. Thus, ambulatory assessment studies are encouraged for more accurate information in the future [48].

In terms of the research framework, this research does not test the whole framework of AET, despite the results supporting that work environment features lead to workplace events, which in turn generate employee affective states and attitudes (i.e., job satisfaction). According to Weiss and Cronpanzano [25], individual traits may moderate the relationship between work events and affective reactions, since diverse demographic and personal characteristics may lead to different preferences and expectations toward the workplace. Therefore, future research may include personal characteristics, (e.g., self-efficacy, emotional intelligence) and other demographic variables (e.g., gender, age, position, family structure, and household status) to investigate the relationship among work environment features, work events, affective reactions, and attitudes on both individual and organizational performance while implementing HPWS [25].

Author Contributions: P.-C.C. and T.W. contributed to research design, data analysis, and manuscript writing. C.-L.L. assisted with the research process. All authors have read and approved the final manuscript.

Funding: This research was funded by [the Faculty Research Grants, Macau University of Science and Technology] grant number [0318].

Conflicts of Interest: The authors declare no conflict of interest.

\section{References}

1. Arthur, J.B. Effects of human resource systems on manufacturing performance and turnover. Acad. Manag. J. 1994, 37, 670-687.

2. Huselid, M.A. The impact of human resource management practices on turnover, productivity and corporate performance. Acad. Manag. J. 1995, 38, 635-672.

3. MacDuffie, J.P. Human resource bundles and manufacturing performance: Organizational logic and flexible production systems in the world auto industry. ILR Rev. 1995, 48, 197-221. [CrossRef]

4. Ramsay, H.; Scholarios, D.; Harley, B. Employee and high-performance work systems: Testing inside the black box. Br. J. Ind. Relat. 2000, 38, 501-531. [CrossRef]

5. Appelbaum, E.; Bailey, T.; Berg, P.; Kalleberg, A.L. Manufacturing Advantage: Why High Performance Work Systems Pay Off; ILR Press: Ithaca, NY, USA, 2000.

6. Boselie, P.; Brewster, C.; Paauwe, J. In search of balance-managing the dualities of HRM: An overview of the issues. Per. Rev. 2009, 38, 461-471. [CrossRef]

7. Lepak, D.P.; Liao, H.; Chung, Y.; Harden, E.E. A conceptual review of human resource management systems in strategic human resource management research. In Research in Personnel and Human Resources Management; Emerald Group Publishing Limited: Bingley, UK, 2006; Volume 25, pp. 217-271.

8. Su, Z.-X.; Wright, P.M. The effective human resource management system in transitional China: A hybrid of commitment and control practices. Int. J. Hum. Resour. Manag. 2012, 23, 2065-2086. [CrossRef]

9. Ogbonnaya, C.N.; Valizade, D. Participatory workplace activities, employee-level outcomes and the mediating role of work intensification. Manag. Res. Rev. 2015, 38, 540-558. [CrossRef]

10. Zhang, B.; Morris, J.L. High-performance work systems and organizational performance: Testing the mediation role of employee outcomes using evidence from PR China. Int. J. Hum. Resour. Manag. 2014, 25, 68-90. [CrossRef] 
11. Zhou, Y.; Liu, X.-Y.; Hong, Y. When western HRM constructs meet Chinese contexts: Validating the pluralistic structures of human resource management systems in China. Int. J. Hum. Resour. Manag. 2012, 23, 3983-4008. [CrossRef]

12. Kramar, R. Beyond strategic human resource management: Is sustainable human resource management the next approach? Int. J. Hum. Resour. Manag. 2014, 25, 1069-1089. [CrossRef]

13. Mak, A.; Cheung, L.; Mak, A.; Leung, L. Confucian thinking and the implications for sustainability in HRM. Asia-Pac. J. Bus. Adm. 2014, 6, 173-189. [CrossRef]

14. Zhang, M.; Zhu, C.J.; Dowling, P.J.; Bartram, T. Exploring the effects of high-performance work systems (HPWS) on work-related well-being of Chinese hospital employees. Int. J. Hum. Resour. Manag. 2013, 24, 3196-3212. [CrossRef]

15. Sparham, E.; Sung, J. High Performance Work Practices-Work Intensification or "Win-Win"? Center for Labor Market Studies, University of Leicester: Leicester, UK, 2007.

16. Godard, J. High performance and transformation of work? The implications of alternative work practices for the experience and outcomes of work. ILR Rev. 2001, 54, 776-805. [CrossRef]

17. Godard, J. A critical assessment of the high performance paradigm. Br. J. Ind. Relat. 2004, 42, 349-378. [CrossRef]

18. Paauwe, J. HRM and performance: Achievement, methodological issues and prospects. J. Manag. Stud. 2009, 46, 129-142. [CrossRef]

19. De Stefano, F.; Bagdadli, S.; Camuffo, A. The HR role in corporate social responsibility and sustainability: A boundary-shifting literature review. Hum. Resour. Manag. 2018, 57, 549-566. [CrossRef]

20. Mariappanadar, S.; Kramar, R. Sustainable HRM: The synthesis effect of high performance work systems on organizational performance and employee harm. Asia Pac. J. Bus. Adm. 2014, 6, 206-224. [CrossRef]

21. Mignonac, K.; Herrbach, O. Linking work events, affective states and attitudes: An empirical study of managers' emotions. J. Bus. Psychol. 2004, 19, 221-240. [CrossRef]

22. Obrad, C.; Gherheș, V. A Human Resources Perspective on Responsible Corporate Behavior. Case Study: The Multinational Companies in Western Romania. Sustainability 2018, 10, 726. [CrossRef]

23. Mariappanadar, S. Sustainable human resource strategy: The sustainable and unsustainable dilemmas of retrenchment. Int. J. Soc. Econ. 2003, 39, 209-220. [CrossRef]

24. Kim, S.; Wright, P.K.; Su, Z. Human resource management and firm performance in China: A critical review. Asia Pac. J. Hum. Resour. 2010, 48, 58-85.

25. Weiss, H.M.; Cropanzano, R. Affective events theory: A theoretical discussion of the structure, causes and consequences of affective experiences at work. In Research in Organizational. Behavior; Staw, B.M., Cummings, L.L., Eds.; JAI Press: New York, NY, USA, 1996; Volume 18, pp. 1-74.

26. Mostafa, A.M.S. High-performance HR practices, positive affect and employee outcomes. J. Manag. Psychol. 2017, 32, 163-176. [CrossRef]

27. Boxall, P.; Macky, K. High-involvement work processes, work intensification and employee well-being. Work Employ. Soc. 2014, 28, 963-984. [CrossRef]

28. Wood, S.; Van Veldhoven, M.; Croon, M.; de Menezes, L.M. Enriched job design, high involvement management and organizational performance: The mediating roles of job satisfaction and well-being. Hum. Relat. 2012, 65, 419-445. [CrossRef]

29. Karasek, R.A., Jr. Job demands, job decision latitude, and mental strain: Implications for job redesign. Adm. Sci. Q. 1979, 24, 285-308. [CrossRef]

30. Avgar, A.C.; Pandey, N.; Kwon, K. Discretion in context: A moderated mediation model of the relationship between discretion and turnover intentions. Ind. Relat. 2012, 51, 106-128. [CrossRef]

31. Lu, C.M.; Chen, S.J.; Huang, P.C.; Chien, J.C. Effect of diversity on human resource management and organizational performance. J. Bus. Res. 2015, 68, 857-861. [CrossRef]

32. Jensen, J.M.; Patel, P.C.; Messersmith, J.G. High-performance work systems and job control: Consequences for anxiety, role overload, and turnover intentions. J. Manag. 2013, 39, 1699-1724. [CrossRef]

33. Kroon, B.; van de Voorde, K.; van Veldhoven, M. Cross-level effects of high-performance work practices on burn-out: Two counteracting mediating mechanisms compared. Pers. Rev. 2009, 38, 509-525. [CrossRef]

34. Wegge, J.; van Dick, R.; Fisher, G.K.; West, M.A.; Dawson, J.F. A test of basic assumptions of Affective Events Theory (AET) in call center work. Br. J. Manag. 2006, 17, 237-254. [CrossRef] 
35. Macky, K.; Boxall, P. High-involvement work process, work intensification and employee well-being: A New Zealand worker experiences. Asia Pac. J. Hum. Resour. 2008, 46, 38-55. [CrossRef]

36. Burke, M.J.; Brief, A.P.; Georg, J.M.; Roberson, L.; Webster, J. Measuring affect at work: Confirmatory analysis of competing mood structures with conceptual linkage to cortical regulatory systems. J. Pers. Soc. Psychol. 1989, 57, 1091-1102. [CrossRef] [PubMed]

37. Brayfield, A.H.; Rothe, H.F. An index of job satisfaction. J. Appl. Psychol. 1951, 35, 307-311. [CrossRef]

38. Hofmann, D.A. An overview of the logic and rationale of hierarchical linear models. J. Manag. 1997, 23, 723-744. [CrossRef]

39. Baron, R.M.; Kenny, D.A. The moderator-mediator variable distinction in social Psychol. research: Conceptual, strategic, and statistical considerations. J. Pers. Soc. Psychol. 1986, 51, 1173-1182. [CrossRef] [PubMed]

40. Krull, J.L.; MacKinnon, D.P. Multilevel modeling of individual and group level mediated effects. Multivar. Behav. Res. 2001, 36, 249-277. [CrossRef] [PubMed]

41. Barrena-Martinez, J.; López-Fernández, M.; Romero-Fernandez, P.M. Drivers and barriers in socially responsible human resource management. Sustainability 2018, 10, 1532. [CrossRef]

42. Harley, B. Employee responses to high performance work system practices: An analysis of AWIRS95 data. J. Ind. Relat. 2002, 44, 418-434. [CrossRef]

43. Shen, J. Employees' satisfaction with HRM in Chinese privately-owned enterprises. Asia Pac. Bus. Rev. 2010, 16, 339-354. [CrossRef]

44. Hofstede, G. Culture and Organizations; McGraw-Hill: New York, NY, USA, 1991.

45. Baruch, Y. Response rate in academic studies-A comparative analysis. Hum. Relat. 1999, 52, $421-438$. [CrossRef]

46. Podsakoff, P.M.; MacKenzie, S.B.; Lee, J.-Y.; Podsakoff, N.P. Common method biases in behavioral research: A critical review of the literature and recommended remedies. J. Appl. Psychol. 2003, 88, 879-903. [CrossRef] [PubMed]

47. Podsakoff, P.M.; MacKenzie, S.B.; Lee, J.-Y.; Podsakoff, N.P. Sources of method bias in social science research and recommendations on how to control it. Annu. Rev. Psychol. 2012, 63, 603-609. [CrossRef] [PubMed]

48. Klumb, P.; Elfering, A.; Herre, C. Ambulatory assessment in industrial organizational psychology: Fruitful examples and methodological issues. Eur. Psychol. 2009, 14, 120-131. [CrossRef] 